\title{
Os mercados da ovinocultura na pecuária familiar: proposições analíticas da Nova Sociologia Econômica
}

\author{
Markets of sheep farming in family livestock: analytical \\ propositions of the New Economic Sociology
}

\author{
Rodrigo Gisler Maciel ${ }^{1}$ (D), Cláudio Becker² (D) e Márcio Zamboni Neske²
}

\begin{abstract}
Resumo: Ao revisitar os aportes teóricos da nova sociologia econômica e suas principais contribuições ao estudo dos mercados, buscou-se refletir sobre formas alternativas de compreender a natureza e o funcionamento dos mercados da ovinocultura na pecuária familiar do Rio Grande do Sul, território historicamente atrelado à criação da espécie ovina. Dessa forma, discorreu-se no estilo de um ensaio teórico sobre as principais perspectivas teórico-metodológicas utilizadas atualmente no estudo dos mercados da ovinocultura, suas contribuições e limitações e, de forma complementar, são apresentadas proposições para o estudo dos mercados da ovinocultura na pecuária familiar a partir das recomendações encontradas na abordagem da nova sociologia econômica. Considerações são tecidas em relação ao potencial desta abordagem no que diz respeito à elaboração de uma tipologia para aqueles mercados, contemplando o entendimento do processo de construção social dos mesmos.
\end{abstract}

Palavras-chaves: ovinocultura, pecuária familiar, mercados, Nova Sociologia Econômica.

\begin{abstract}
Revisiting the theoretical contributions of the new economic sociology and its main contributions to the study of the markets, this article aims to reflect on alternative ways of understanding the nature and functioning of sheep markets in the family livestock of Rio Grande do Sul, which is historically linked to the creation of ovine species. In this way, a theoretical essay was presented on the main theoretical-methodological perspectives currently used in the study of sheep markets, their contributions and limitations, and in addition, propositions are presented for the study of the sheep industry markets on family livestock from the recomendations found in the approach of the new economic sociology. Considerations about the potential of this approach with regard to the elaboration of a typology for those markets are presented, including the understanding of the process of social construction.
\end{abstract}

Key-words: sheep production, family livestock, markets, New Economic Sociology.

Classificação JEL: Z13.

Data de submissão: 18 de abril de 2017. Data de aceite: 28 de julho de 2018.

1. Universidade Federal do Rio Grande do Sul, Porto Alegre, (RS), Brasil.

E-mail: rodrigo.gisler@gmail.com

2. Universidade Estadual do Rio Grande do Sul, Santana do Livramento, (RS), Brasil. E-mails: cldbecker@gmail.com; marcio.neske@gmail.com 


\section{Introdução}

A sociedade do Rio Grande do Sul tem sua historicidade fortemente atrelada ao desenvolvimento da pecuária, na qual traços culturais, econômicos e ambientais em diferentes períodos de tempo e espaço mesclam-se com as várias formas de ocupação territorial, sistemas de produção, estrutura fundiária e organização dos mercados agrícolas. Em meio a esse amálgama, a pecuária ovina se destaca como uma atividade produtiva característica do território em questão. O processo de ocupação territorial pautado na concessão de sesmarias resultou em uma estrutura fundiária demasiadamente concentrada no Rio Grande do Sul, principalmente em regiões de fronteira, marcadas pela existência de grandes propriedades ocupadas predominantemente pela pecuária extensiva. Porém, segundo Osório (2016), apesar da imagem mormente difundida da fronteira oeste gaúcha desse período, caracterizada por extensas áreas de campo (estâncias), poucos homens e muito gado, o cenário agrário desse território foi constituído por sistemas produtivos e uma sociedade bem mais complexa.

Neste sentido, a origem da criação ovina no Rio Grande do Sul ocorreu em uma diversificada paisagem agrária, com predomínio de sistemas produtivos mistos e grande parcela dos estabelecimentos rurais com rebanhos de até 200 cabeças (Osório, 2016). Conforme Fernandes \& Miguel (2016), o território gaúcho apresentava, já nos séculos XVIII e XIX, criadores de gado de pequeno e médio porte atuando com os grandes criadores, caracterizados por terem menores áreas de terra, uso de mão de obra predominantemente familiar e relativa autonomia em relação ao mercado, categoria social denominada pecuaristas familiares. Esse segmento social presente nos campos sulinos no século XIX, segundo Fernandes \& Miguel (2016), tinha pequenos rebanhos ovinos, destinados mormente para o consumo das famílias.

A fronteira oeste do Rio Grande do Sul se manteve como principal região produtora de ovinos no estado durante o século XX, participando atualmente em cerca de 39\% do rebanho gaúcho, com efetivo de 1.556 .867 cabeças (Instituto Brasileiro De Geografia \& Estatística, 2016). Estima-se existir um total de 8.444 estabelecimentos rurais dedicados à pecuária ovina na região, aproximadamente 17\% do total estadual (Secretaria da Agricultura Pecuária e Irrigação do Rio Grande do Sul, 2012) e, conforme dados do Censo Agropecuário de 2006, cerca de 65\% têm área de até 200 hectares, destacando-se o número de estabelecimentos com esta atividade que possuem de 20 a 50 hectares, cerca de $20 \%$ do total regional (Instituto Brasileiro de Geografia e Estatística, 2007). Percebe-se que a produção ovina é hoje realizada na região predominantemente por pecuaristas familiares, assemelhando-se ao cenário verificado por Fernandes \& Miguel (2016) no século XIX. Assim, o contexto atual destoa, em grande medida, daquela imagem usualmente aceita pelo senso comum de que a produção dá-se, fundamentalmente, em grandes fazendas com restritas relações sociais no seu interior (originadas nas estâncias comerciais do final do século XIX). Certamente, esta é parte do atual contexto da pecuária no Rio Grande do Sul; 
porém, verifica-se que um grande número de pequenas propriedades rurais desenvolveu-se juntamente com a ovinocultura nos campos do estado.

Com base na atual estrutura produtiva, e considerando as mudanças na configuração do setor após a década de 1990, Viana \& Silveira (2009) sugerem uma reorientação da ovinocultura gaúcha, voltando-se para produção de carne ovina. Corroborando esse aspecto, Felice et al. (2011) indicam tendência positiva nos abates de ovinos entre 2002 e 2011, externando o viés da produção ovina para os mercados de carnes. Fundamentado na ideia de "reorientação da ovinocultura gaúcha", diversos agentes de desenvolvimento vêm atuando no sentido de explanar e conjecturar mercados para esta atividade pecuária. No âmbito das políticas públicas, a criação de um fundo de desenvolvimento setorial, programas, projetos e ações de incentivo a reestruturação da cadeia produtiva são observados (Rio Grande do Sul, 1998; Secretaria da Agricultura Pecuária e Irrigação do Rio Grande do Sul, 2016). No mesmo sentido, esforços de articulação dos atores envolvidos na ovinocultura estadual, como encontros, seminários e simpósios, centrados na elevação da competitividade do setor são visualizados com maior intensidade (Expointer, 2016; Serviço Brasileiro de Apoio às Micro e Pequenas Empresas, 2016; Simpósio de Ovinos, 2016).

Atualmente, pesquisas acadêmicas que possuem como mote os mercados da ovinocultura, usualmente embasadas em abordagens economicistas e nos preceitos do agribusiness, fundamentam a miúdo, e tomam como objeto de análise, as ações empíricas acima citadas. Observam-se nestes estudos aspectos relacionados à competitividade, modernização, integração e coordenação das cadeias produtivas, bem como os gargalos e desafios da ovinocultura (Barchet, 2012; Canozzi, 2013; Decker et al., 2016; Viana et al., 2012; Viana et al., 2013). Considerações sobre a heterogeneidade presente na produção ovina, a participação da pecuária familiar, bem como a pluralidade de seus mercados são muitas vezes menosprezadas nas pesquisas acadêmicas atualmente conduzidas. Por outro lado, observam-se na literatura algumas pesquisas voltadas a investigar tais questões, com ênfase na construção social dos mercados para a ovinocultura e nas estratégias de enfrentamento da produção de base familiar frente à homogeneização dos mercados (Anjos et al., 2016; Matte et al., 2016; Van Der Ploeg, 2016; Waquil et al., 2016).
A pouca relevância atribuída pela perspectiva da competitividade nas cadeias produtivas em relação à heterogeneidade dos pecuaristas familiares, no que diz respeito a seus modos de produção e relações com os mercados, resultam geralmente na vinculação desta categoria social com a ineficiência do setor, apresentando-os de forma marginal e limitando os estudos de seus mercados. Por outro lado, autores interessados na produção de base familiar consideram a diversidade existente nos seus modos de vida e de produção; porém, com restritos estudos sobre os mercados da pecuária familiar, sobretudo da ovinocultura. Identifica-se, dessa forma, uma carência no que diz respeito a estudos dos mercados da pecuária familiar, assim como na proposição de aportes teórico-metodológicos para análise dos mesmos.

Assim sendo, a abordagem da sociologia econômica, que se ocupa com o estudo dos mercados como produtos históricos da interação entre atores sociais imersos em determinadas sociedades (Steiner, 2006), vem sendo cada vez mais utilizada por pesquisadores que intentam clarificar questões sobre a interação entre as relações mercantis, estrutura social e as estratégias de desenvolvimento no meio rural (Niederle et al., 2014; Schneider, 2016). Tal abordagem possibilita uma visão distinta daquelas promovidas por pesquisas com viés puramente economicista das relaçóes entre os atores sociais ligados à pecuária ovina, ao considerar o caráter histórico e relacional da construção e funcionamento dos mercados. A chamada Nova Sociologia Econômica (NSE) emerge como uma abordagem sociológica da vida econômica, a qual parte dos pressupostos de enraizamento dos fenômenos econômicos em estruturas e redes sociais, e da perspectiva social construtivista na interpretação das instituições econômicas (Raud-Mattedi, 2005). Desse modo, pesquisadores voltados a questões do meio rural adquirem os aportes necessários para melhor compreensão da heterogeneidade presente nos mercados da agricultura e pecuária familiares, possibilitando, conforme indicado por Niederle et al. (2014), a visualização de múltiplos mercados além do dualismo dos mercados globalizados e dos mercados localizados.

O presente estudo possui como objetivo revisitar os aportes teóricos da (nova) sociologia econômica e suas principais contribuições ao estudo dos mercados e, dessa forma, refletir e propor formas alternativas de compreender a realidade da ovinocultura da pecuária familiar do Rio Grande do Sul, em especial quanto 
à natureza e ao funcionamento dos mercados desta categoria social.

A forma e o estilo de apresentação deste estudo, através de um ensaio teórico, deve-se à necessidade do exercício de reflexão sobre a temática em questão, anterior a quaisquer investigações científicas com caráter mais formalista. Entende-se, dessa forma, que a premência de uma análise crítica sobre os mercados da ovinocultura antecede a condução de pesquisas descritivas e/ou prescritivas sobre estes mercados, sobretudo quanto às abordagens alternativas para o estudo da pecuária familiar. Neste sentido, a possibilidade de despir-se do rigor metodológico, presente na pesquisa científica tradicional, e ocupar-se particularmente na reflexão como forma de compreensão da realidade, conduziu a definição do estilo de ensaio teórico na realização deste trabalho.

O artigo estrutura-se, além desta seção introdutória, de uma exposição dos fundamentos teóricos que balizam a compreensão dos mercados como instituições socialmente construídas, voltando-se, assim, à temática da nova sociologia econômica. Aplicações desta corrente teórica nos estudos do rural são expostos nesta seção. Em seguida, é apresentada uma revisão do estado da arte sobre os mercados da ovinocultura, ressaltando suas principais contribuições e limitações em relação à pecuária familiar. Alicerçado nas discussões realizadas nos tópicos anteriores e analisando a ovinocultura dentro da concepção de pecuária familiar, busca-se indicar algumas proposições para o estudo dos mercados da pecuária ovina. Para finalizar, são delineadas as considerações finais do ensaio.

\section{Concepção dos mercados sob a ótica da Nova Sociologia Econômica}

O presente tópico tem como objetivo explorar os fundamentos da corrente teórica da nova sociologia econômica, assim como identificar, através de aplicações no âmbito dos estudos rurais, elementos que favoreçam a compreensão dos mercados da ovinocultura gaúcha. Neste sentido, parte-se das recentes e significativas contribuições realizadas por Schneider (2016) e Wilkinson (2016) à literatura da área.
Com o intuito de refletir sobre os vínculos entre a agricultura familiar e os mercados, Schneider (2016) ressalta a atualidade do debate proposto por Wilkinson (2008) em torno da polarização entre a ampliação do mercado mundial de commodities e a emergência de mercados alternativos e cadeias produtivas localizadas. O autor ainda destaca que, até o início do século XXI, era restrita a participação de pesquisadores neste debate, sobretudo os cientistas sociais rurais, devido principalmente a certo desconforto ao identificarem os mercados como sinônimo de economia de mercado (Schneider, 2016). A assimilação do conceito de mercados com a ideia de capitalismo, ou mesmo de economias de mercado, pode ser atribuída ainda ao forte dualismo com que vêm sendo tratados os estudos rurais. Conforme Wilkinson (2016), os mercados são vistos geralmente de forma antagônica, por um lado, sob a lógica de mercado maximizadora de lucros (relacionados a termos como dominante, "de commodities" ou mainstream) e, por outro, submetendo essa lógica às relações sociais (associados à noção de redes, locais, enraizados ou de cadeias curtas).

Apesar do forte dualismo na concepção dos mercados e consequente desinteresse de parte dos cientistas sociais rurais, ponderações são feitas por Niederle et al. (2014) quanto à importância destes como estruturas sociais de maior impacto nas transformações das sociedades, antes mesmo do desenvolvimento do capitalismo. Ainda, reforçando a tese de os mercados caracterizarem-se sobretudo como fatos sociais, estando sujeitos, assim, à análise da sociologia rural, Schneider (2016) sugere que:

[...] os mercados fazem parte dos processos sociais de produção e reprodução das atividades econômicas e das unidades familiares, influenciam a vida das pessoas, os seus valores e sua cultura, moldam e modificam instituições e são motivo para conflitos, protestos e disputas (Schneider, 2016, p. 95).

Empenhando-se em superar o senso comum sobre "o mercado" como uma instituição única na sociedade, caracterizada por um ambiente de competição baseado no sistema de preços, Schneider (2016, p. 97) se vale de três percepções sobre os mercados: (i) "o mercado como um locus", sítio específico onde são realizadas as trocas de mercadorias; (ii) "o mercado como princípio ordenador da sociedade e da economia", assemelhando-se à ideia do capitalismo; e (iii) "o mercado como uma construção social", derivado da interação entre atores imersos 
em uma estrutura social. Essa última corrobora com a ideia apoiada por Wilkinson (2016) quanto às relações entre mercados e sociedade. Assim sendo, o termo sociologia econômica refere-se a uma abordagem teórica que, conforme Weber (1949 apud Swedberg, 2004), se ocupa do estudo dos fenômenos econômicos dentro das sociedades: tanto a forma que estes influenciam a sociedade como os meios pelos quais a sociedade os influenciam. A análise dos fenômenos econômicos sob o prisma da sociologia econômica iniciou-se no final do século XIX, em que intelectuais das ciências sociais encontravam-se insatisfeitos com a rigorosa aplicação matemática da economia política do período, principalmente o desenvolvimento da teoria da utilidade marginal.

O desenvolvimento das teorias associadas à análise utilitarista converge com o período histórico, pós-mercantilismo, em que os mercados passam a serem compreendidos como "princípio ordenador da sociedade e da economia" (Schneider, 2016), pautado essencialmente na contribuição de Adam Smith sobre a "mão invisível" que conduz o mercado a um estado de equilíbrio geral. A partir do século $\mathrm{XX}$, a análise dos mercados torna-se objeto específico das correntes liberais, lideradas pelo utilitarismo da escola austríaca (conduzida por Menger e Walras), o pensamento neoclássico com sua racionalidade matemática torna-se absoluto na proposição de modelos interpretativos do(s) mercado(s) (Niederle et al., 2014).

Autores clássicos da economia e sociologia, como Durkheim, Marx, Pareto, Schumpeter e Weber, fundam, sob distintas formas, o estudo da sociologia dos mercados em face à economia política da época e o pensamento econômico neoclássico (Steiner, 2006; Swedberg, 2004). Assim, alicerçado no conceito de ação social, Max Weber reforça a dimensão socializadora das relações mercantis, considerando o ator econômico não como um autômato, que reflete as indicações do mercado, mas através de um conjunto de valores subjetivos, enraizados em instituições socialmente construídas (Steiner, 2006). Esta concepção coloca Weber como o principal nome da chamada "sociologia econômica clássica". Contudo, foi a obra "A grande transformação", de Karl Polanyi que, ao apontar para as rupturas da sociedade causadas pelo desenvolvimento do capitalismo, oferece subsídios para a formação da agenda de pesquisa futura, denominada "Nova Sociologia Econômica". Em sua obra, Polanyi (1980) argumenta que as relações mercantis generalizaram-se de tal modo no capitalismo que o homem e a natureza transformam-se em mercadorias, na forma de trabalho e terra e, ainda, a chamada economia de mercado emerge uma sociedade de mercado, relegando a sociedade à lógica do(s) mercado(s).

A noção de "enraizamento" (embeddedness) é apresentada por Polanyi (1980) como forma de dizer que os fenômenos econômicos têm sua natureza nos atores sociais e em suas relações (estruturas sociais, ou em parte destas), indicando, assim, a não existência do homo economicus (Swedberg, 2004). Assim, o enraizamento da economia torna-se a principal contribuição de Polanyi à nova sociologia econômica, ao ser tomado (e retrabalhado) por Mark Granovetter, considerado pioneiro e um dos principais autores dessa corrente teórica (Steiner, 2006; Swedberg, 2004; Wilkinson, 2008). Conforme Wilkinson (2008), a ideia de enraizamento suscita duas questões centrais para a sociologia econômica: (i) a economia encontra-se enraizada em quê?; (ii) qual é o grau desse enraizamento?. Ainda conforme o autor, a primeira questão pode ser interpretada por meio de quatro abordagens: política, cultural, social e científica. Neste sentido, Wilkinson (2008) ainda indica autores relacionados às abordagens mencionadas como forma de compreender a lógica de enraizamento do fenômeno econômico analisado, respectivamente Neil Fligstein, Paul DiMaggio, Mark Granovetter e Michel Callon. Quanto à questão sobre o grau de enraizamento da economia, é sugerida por Wilkinson (2008) a concepção de enraizamento formada por Granovetter, através da análise de redes sociais, como forma de interpretá-la. Neste sentido, em sua profícua obra, Granovetter (1985) rejeita a visão antagônica da economia enraizada ou desenraizada da estrutura social, através de um posicionamento radical sobre as interpretações dos mercados pela economia neoclássica e a nova economia institucional, as quais dão um tratamento "socializado de menos" para os mercados, assim como algumas abordagens que tendem a uma visão "socializada demais"1. Para o autor:

1 Conforme Raud-Mattedi (2005), assim como a tradição de Max Weber, ao propor uma sociologia econômica complementar à teoria econômica, Granovetter não se posiciona a partir de um olhar contrário à economia neoclássica, mas, sim, objetivando apresentar novas contribuições às questões abertas por esta abordagem teórica e não totalmente respondidas. Granovetter, dessa forma, indica as proposições da nova sociologia econômica como complementares àquelas abordagens econômicas dos mercados. 
The embeddedness approach to the problem of trust and order in economic life, then, threads its way between the oversocialized approach of generalized morality and the undersocialized one of impersonal, institucional arrangements by following and analyzing concrete patterns of social relations (Granovetter, 1985, p. 493).

Assim, Granovetter (1985) propõe uma forma de explicação para o funcionamento dos mercados a partir de um olhar das relações sociais, ou seja, a natureza das redes sociais em que estão inseridos os atores, e a posição dos mesmos, deve ser o ponto inicial da análise dos mercados. Uma rede social, dessa forma, pode ser descrita como um conjunto de atores sociais que criam um certo tipo de vínculo (laços) a partir das relações entre si, variando conforme graus de frequência, especificidade e similaridade, ou seja, a rede pode ser concebida como a estrutura das relações sociais (Granovetter, 1985; Steiner, 2006; Swedberg, 2004).

O posicionamento dos atores na rede social é considerado fundamental na obra de Granovetter, em que, a partir da identificação do papel estratégico dos atores localizados nos pontos de interligação (nós) entre distintas redes, o autor lança mão do conceito de "laços fracos", como essenciais na compreensão da formação e funcionamento dos mercados (Wilkinson, 2008). Assim, segundo Raud-Mattedi (2005), a ideia de laços fracos está associada a um dos tipos de enraizamento propostos por Granovetter ${ }^{2}$, referindo-se aos laços mantidos pelos atores com conhecidos (não intimamente próximos), proporcionando-lhes contato com meios sociais diferentes. A partir da ênfase nas relações entre redes sociais e a formação dos mercados, e especificamente a partir da noção de "laços fracos", segundo Wilkinson (2008), o esforço da nova sociologia econômica desloca-se da perspectiva de enraizamento para uma visão social construtivista, relacionando o funcionamento dos mercados com o tipo de rede social em que está inserido. Mais explicitamente, ao realizar sua análise sobre as instituições, Granovetter direciona crítica à visão neoinstitucionalista da economia, a qual

\footnotetext{
2 Em publicação de 1990, Granovetter distingue dois tipos de enraizamento da economia, o relacional e o estrutural. $\mathrm{O}$ enraizamento relacional refere-se às relações pessoais, mais íntimas dos atores. Já o enraizamento estrutural está precisamente vinculado à noção de "laços fortes" (relações mais próximas, como parentes e amigos próximos) e de "laços fracos" (relações sustentadas com conhecidos) (Raud-Mattedi, 2005).
}

assevera que as instituições existentes são o resultado mais eficiente de disputas entre distintas opções; porém, sem definição concreta de eficiência, e ainda sugere que as instituições são condicionadas pela configuração das redes sociais, ou seja, estão enraizadas nas ações e estruturas sociais (Raud-Mattedi, 2005).

Assim, para Raud-Mattedi (2005), a contribuição de Granovetter, através de sua "sociologia da vida econômica", pode ser discriminada pela análise de três níveis de fenômenos econômicos: a ação econômica; os resultados econômicos e as instituições econômicas. Portanto, da mesma forma que para Raud-Mattedi, o primeiro e o último nível têm maior enfoque no presente ensaio, de tal modo que três pressupostos dirigem as reflexões de Granovetter na análise destes fenômenos: (i) a ação econômica é um modo de ação social; (ii) a ação econômica é assentada em uma estrutura (rede) social (noção de enraizamento) e (iii) as instituições econômicas são socialmente construídas.

Complementarmente à análise dos mercados como instituições imersas em redes sociais, Radomsky \& Schneider (2007) propõem o diálogo entre noção de redes com a teoria da reciprocidade, no intuito de traçar referenciais analíticos para o estudo da natureza do vínculo social. A reciprocidade parte da noção da dádiva, descrita como "qualquer ação sem expectativa imediata ou certeza de retribuição" (Radomsky \& Schneider, 2007, p. 253-254), sendo a reciprocidade a reprodução da própria dádiva em um mesmo ato - fundamento da troca (ato carregado com potencial de sociabilidade humana, solidificando relações e redes sociais). Assim, os autores indicam as relações de reciprocidade como forma de manutenção dos laços que fundamentam as redes (e consequentemente os mercados, a partir dos preceitos de uma economia moral implícita à economia material). Precisamente, a confiança existente nos laços sociais, fator fundamental na formação (e na espessura) de uma rede social (como indicado por Granovetter), é fortemente induzida pelas relações de reciprocidade (Radomsky \& Schneider, 2007; Raud-Mattedi, 2005).

Do mesmo modo, Schneider (2016) atenta para os aportes da teoria da reciprocidade em relação ao estudo dos mercados da agricultura familiar, essencialmente quando consideradas as relações de trocas, em que, por exemplo, os escambos e os intercâmbios de animais e sementes baseiam-se essencialmente no princípio da reciprocidade. Ainda, valendo-se dos princípios de 
integração social propostos por Polanyi (1980), o autor apresenta o gradiente dos potenciais modos de organização das sociedades, indo de relações puramente baseadas nos princípios da reciprocidade até as formas de intercâmbios mercantilizadas, em que o mercado passa a funcionar como princípio ordenado da economia e das instituições sociais e, como forma intermediária, o princípio de redistribuição e centralidade, relacionado a padrões de ordenamento político da sociedade (Schneider, 2016).

Duas assertivas acerca dos princípios de integração social são apontadas: (i) as três formas podem coexistir em distintas condições de tempo e espaço, não sendo excludentes entre si e (ii) não existe um caminho único no processo de integração dos agricultores familiares aos mercados, de uma economia camponesa à mercantilização capitalista (Schneider, 2016). De tal forma, ao analisar e descrever a existência de múltiplos mercados para a agricultura familiar sob a ótica da sociologia econômica, Niederle et al. (2014) apontam que, a partir da compreensão da existência de distintas configurações sociais e institucionais visualiza-se a existência de múltiplos mercados, não no sentido dualístico de mercados globalizados e localizados, mas sobrepostos em distintos níveis espaciais e temporais. Considerações sobre a construção de tipologias dos múltiplos mercados para a agricultura familiar são tecidas por Schneider (2016), tomando como base as percepções sobre os mercados, indicadas no início deste tópico. Assim, o autor considera os mercados a partir de uma perspectiva de lugar ou espaço onde ocorrem as transações, caracterizando-se desde uma troca local (baseada nos princípios da dádiva), em trocas de nível regional ou territorial, e, naquelas sem local definido, baseadas em normas dos chamados mercados gerais (como preços ou contratos).

A segunda forma de conceber os mercados relaciona-se diretamente com a primeira, no momento em que os mercados caminham espacialmente para uma maior distância entre agricultores e consumidores, os mecanismos de intercâmbio mercantil passam a funcionar como princípio normativo da economia e sociedade, relegando os agricultores às "leis do mercado". O terceiro ponto de vista sobre os mercados refere-se à abordagem teórica comentada no centro desta seção do ensaio, que entende os mercados como construções sociais, sendo esta a perspectiva balizadora da formação das tipologias propostas por Schneider (2016) para os mercados da agricultura familiar, sendo estas:

a) Mercados de proximidade-são mercados conformados em um locus específico, geralmente próximos aos agricultores (no local), com predomínio de relações de trocas interpessoais, e valorizando aspectos intrínsecos dos produtos e das relações acima do lucro em si. São mercados socialmente construídos, enraizados em relações de reciprocidade, a qual exerce papel de controle e regulação do mesmo. Caracterizados pelos agricultores camponeses, produtores de excedentes;

b) Mercados locais e territoriais - são mercados caracterizados por agricultores familiares, com produção simples de mercadorias, em que as trocas são monetizadas. Mesmo com características dos mercados de proximidade, em relação aos valores imbuídos nas trocas, o objetivo passa a ser o ganho na troca, enviesando-se a uma economia mercantil simples. Possui um locus vinculado a determinado local, porém com canais de comercialização mais amplos (marcas dos processos de desterritorialização). Nestes casos, a reciprocidade e o interconhecimento passam a conviver com mecanismos de preços e concorrência;

c) Mercados convencionais - são os mercados formados por aqueles que se dedicam a produzir exclusivamente bens e mercadorias com fins de trocas mercantis. Orientado fortemente pelos preceitos da oferta e da demanda, estes tipos de mercados possuem um locus físico "sem lugar", ou seja, posiciona-se nas esferas nacionais e globais de distribuição (principal distinção dos mercados locais e territoriais). Caracterizam-se por terem altos riscos e incertezas, fator que gera, em grande medida, alto grau de vulnerabilidade aos agricultores;

d) Mercados públicos e institucionais - crescente no Brasil, são mercados que possuem como principal agente o Estado, alguma organização pública não governamental ou algum organismo público, assim como o exercício do fair trade. São resultantes de construção social e política, requerendo mecanismos de controle democráticos (pois se originam de contribuições públicas). Não possuem um locus físico de atuação, sendo movidos pela demanda, como alimentação escolar ou outras instituições públicas. 
Conforme Schneider (2016), deve-se atentar que tal tipologia reúne quatro tipos genéricos de interação da agricultura familiar com os mercados, buscando propiciar subsídios para que se possa elaborar uma classificação a partir da heterogeneidade presente no campo empírico. Dessa forma, os tipos sugeridos não se propõem a descrever exatamente como são os mercados em qualquer realidade da agricultura familiar, ademais, o autor adverte para a necessidade constante de um olhar crítico sobre as mudanças agrárias, analisando os processos de inserção dos agricultores nos mercados anteriormente à elaboração de qualquer classificação. Da mesma forma, Niederle et al. (2014) sugerem que, além de reconhecer os mercados como construções sociais, esforços devem ser feitos no sentido de "analisar como as redes são formadas, que fatores levaram a, ou constrangeram a sua constituição, que atores participaram ou foram excluídos" (Niederle et al., 2014, p. 14).

No caso da ovinocultura do Rio Grande do Sul são verificadas dificuldades por parte dos produtores em acessar mercados convencionais, devido, em grande medida, a flutuações de preços, necessidade de escala produtiva e padronização dos animais (Maciel et al., 2013). Ainda, relações de poder estabelecidas através dos canais de comercialização da produção rural por meio dos frigoríficos, devido essencialmente ao "progresso tecnológico engendrado pela modernização da agricultura" (Matte et al., 2016, p.148), resultam na marginalização de um grande número de pecuaristas, sobretudo familiares, evidenciando-se, assim, a necessidade de compreensão da natureza dos mercados da pecuária familiar, seu funcionamento e da averiguação de suas variações em diferentes tipologias.

A abordagem da nova sociologia econômica traz, neste sentido, profícuas contribuições analíticas ao estudo dos mercados da pecuária ovina de base familiar, mostrando-se um referencial cabível quanto a questões sobre a natureza e funcionamento, por meio do seu potencial para elaboração de tipologias dos mercados. A próxima seção apresenta os resultados obtidos em revisão realizada sobre os mercados da ovinocultura baseado em pesquisas recentes, sobretudo no âmbito do Rio Grande do Sul, examinando as principais abordagens teórico-metodológicas utilizadas e discutindo as principais características e limitações quanto à aplicação na realidade da pecuária familiar. A partir desta revisão, apontam-se algumas proposições ao estudo dos mercados da ovinocultura na pecuária familiar.

\section{Perspectivas teórico-metodológicas sobre os mercados da ovinocultura}

A partir do final dos anos 1990 observa-se um crescente interesse nos mercados da ovinocultura gaúcha, o que para Viana \& Silveira (2009) e Felice et al. (2011) deve-se à suposta reorientação do setor, motivada pelo incremento da demanda por carne ovina. No entanto, Viana (2012), ao analisar a mudança estrutural da produção ovina no Rio Grande do Sul após a crise da lã, pondera sobre essa propensão à reestruturação, afirmando que a pecuária ovina não retornou a uma situação de equilíbrio após a crise, mas apresenta-se hoje com motivações, não apenas econômicas, de manutenção das atividades. Mesmo assim, grande parte dos estudos conduzidos na ovinocultura gaúcha partem do enfoque do agronegócio, fundamentadas nas abordagens do Commodity System Approach e da Análise de Filière, com vistas a recomendar estratégias competitivas para as organizações do setor.

Buscando descrever o cenário da ovinocultura gaúcha, a partir da caracterização e análise dos seus elos produtivos, Viana \& Silveira (2009) reforçam a necessidade de consolidação do mercado de carne ovina a partir de ações focadas na melhoria da qualidade dos animais, diversificação dos cortes e estratégias de marketing para elevar o consumo. Em estudo semelhante, Canozzi (2013) sugerem uma cadeia da carne ovina complexa e desorganizada, caracterizada pela sazonalidade produtiva; falta de coordenação; baixa competitividade; falta de profissionalização; altos índices de informalidade e demanda atrelada a aspectos culturais. Com o objetivo de identificar as estruturas de governança nas transações entre produtores e indústrias e os mecanismos de coordenação presentes na ovinocultura do Rio Grande do Sul, Viana et al. (2012) apontam duas estruturas de governança principais: de maneira mais recorrente as transações via mercado e a coordenação horizontal, a partir de contratos informais entre produtores rurais e o segmento frigorífico. Já em pesquisa conduzida por Silveira (2005), sobre a aliança estratégica Conselho Regulador Herval Premium, é descrito um caso de coordenação horizontal marcado fortemente por atividades de planejamento, roteirização, terceirização dos abates e elaboração de marca própria como estratégia de consolidação em mercados latentes, no caso, a carne de cordeiro. 
Ao verificar os determinantes da competitividade da cadeia de carne ovina, Barchet (2012) aponta para governança, coordenação e estruturas de mercado como fundamentais à competitividade da ovinocultura de corte do estado, a partir de uma abordagem de análise estática e, em grande medida, utilitarista do funcionamento dos mercados. Por outro lado, com escopo mais restrito de análise, estudo sobre a competitividade na ovinocultura aponta para necessidade de perceber a pecuária ovina como um negócio empresarial, com foco na modernização dos sistemas de produção e gestão, coordenação dos segmentos produtivos e inserção em novos nichos de mercados (Decker et al., 2016).

Com intuito de investigar os aspectos relacionados à sazonalidade na ovinocultura do Rio Grande do Sul, Maciel et al. (2013) apontam a oferta sazonal de animais para abate como uma consequência da desestruturação da cadeia produtiva, indicando a necessidade de estratégias de estímulo ao consumo de carne ovina por parte dos agentes da cadeia produtiva. Na mesma linha de estudos estratégicos sobre a ovinocultura, porém com delineamento mais propositivo, Malheiros (2013) sugere a aplicação de ações do composto de marketing como estratégia para criação de valor na cadeia produtiva da ovinocultura (Malheiros, 2013). Já para Viana et al. (2013), estratégias como a diferenciação de produtos, segmentação de mercados de nichos, adaptação de plantas frigoríficas e desenvolvimento de imagem regional do produto são indicadas como alternativas à criação de valor na ovinocultura. Nessa perspectiva, são observados nos estudos citados certa incompatibilidade em relação à crescente e segmentada demanda por carne ovina e, por outro lado, gargalos produtivos presentes na cadeia. Por este ângulo, os principais resultados encontrados nos estudos da ovinocultura sob o enfoque do agronegócio são: a necessidade de nova orientação da cadeia para a carne ovina (demanda crescente por carne ovina); a reestruturação da cadeia produtiva; sazonalidade produtiva; baixa disponibilidade de animais; informalidade no abate e comercialização; falta de coordenação e integração entre os elos da cadeia e falta de competitividade frente às demais cadeias produtivas.

Recorrentes são as assertivas encontradas sobre a desorganização da cadeia produtiva e os principais gargalos da ovinocultura gaúcha, como os baixos níveis de coordenação e modernização dos agentes (referências aos agronegócios) e aspectos relacionados à informalidade do setor, que, conforme Zero Hora (2012), cerca de $70 \%$ dos ovinos no RS são abatidos/comercializados informalmente (porém, não existe uma base de cálculo segura para este índice). Ainda, é vagamente apontada nos resultados de tais pesquisas, e explicitamente revelada no estudo de Viana (2012) a relevância de instituições informais e questões culturais no que diz respeito à manutenção e ao incremento da produção de ovinos. Aspectos institucionais não formais, ou seja, aqueles pormenores que se encontram subentendidos nos estudos acima citados, e em parte deles são utilizados de forma a justificar aquilo que as abordagens utilizadas carecem de elementos explicativos, são retratados por outros pesquisadores também focados nos mercados da ovinocultura. Tais pesquisas carregam em comum o viés sociológico com que são tratados os mercados, ou seja, partem de uma perspectiva orientada a conceber os fenômenos econômicos a partir das relações estabelecidas pelos atores sociais, e não como um fato com fim em si mesmo. A sociologia econômica, e sua capacidade de apontar tipologias dos mercados, aporta grande parte destes estudos.

Neste sentido, a construção de mercados aninhados ${ }^{3}$ é apontada por Van Der Ploeg (2016) como condição que progressivamente vem sendo responsável pelo desenvolvimento rural, através da reconstituição da lógica local, reconectando a produção e o consumo. No caso da ovinocultura, o autor descreve a iniciativa criada na Ilha de Texel (Holanda), território que vem sofrendo os efeitos da globalização devido ao avanço das cadeias globais no mercado local, anteriormente baseado na produção em sistemas tradicionais, comercialização e consumo local. Assim, atores sociais do território percebem algumas "lacunas estruturais" e propõem a construção de novo mercado, o "Genuíno Cordeiro Texel", baseado em processo de certificação simultânea dos participantes (criadores de ovinos, abatedouros, restaurantes e açougues), e estabeleceu-se uma nova infraestrutura sociomaterial responsável pela manutenção do modelo de mercado tradicional local, através de um conjunto de normas e recursos coletivamente assumidos.

3 Os mercados aninhados surgem a partir das "lacunas estruturais", as quais "se referem aos fluxos que não se materializam e às relações que não são criadas" (Ploeg, 2016, p. 22) nos mercados gerais. Assim, segundo Ploeg (2016), os mercados aninhados são como pontes que servem para remodelar o fluxo de uma mercadoria ou serviço e rearranjar a natureza das transações, reconstituindo mercados locais ou regionais por meio de modos de governança alternativos. 
Ao estudarem a construção social de novos mercados para caprinovinocultura tradicional e sua interação com o desenvolvimento local, Gonçalves \& Martes (2015) descrevem experiências em três municípios do Nordeste brasileiro sob a perspectiva da sociologia econômica. A partir da convergência de ações induzidas por organizações locais (associações de criadores, ONGs, organizações públicas e universidades) e políticas públicas (Programa do Leite, desenvolvido por meio do Programa de Aquisição de Alimentos - PAA), cria-se uma estrutura na forma de uma "rede de entusiastas da caprinovinocultura", responsável pelo fortalecimento dos laços sociais e incentivo à agricultura/ pecuária familiar.

Também apoiado nos preceitos da sociologia econômica, Anjos et al. (2016) estudam a construção social da qualidade no caso do "Cordeiro Herval Premium". Os autores destacam que a iniciativa trata-se da criação de uma marca coletiva através de um conselho regulador, em que se buscou enfatizar a qualidade associada do produto carne ovina (enfatizando aspectos como o vínculo com o território, imagem do produto, relações de produção etc.). A carência de "engajamento cívico", fator fundamental em iniciativas que visam a valorização da identidade territorial, é frisada pelos autores como um fator limitante à iniciativa. Além desta, outros obstáculos são apontados: lógica fortemente voltada à competição por preços; dificuldades técnicas e logísticas; falta de apoio institucional e falta de comprometimento dos envolvidos.

Em estudo realizado sob a concepção da relocalização alimentar e formação de cadeias curtas, Matte et al. (2016) descrevem o caso do cordeiro do território do Alto Camaquã (RS). Os autores partem do debate em torno da localização como forma de ressignificação da produção e consumo no território, pautados principalmente nos emergentes conceitos de quality turn e de cadeias curtas, enfatizando o aspecto do "enraizamento social do território", e, ainda, trazendo ao debate questões relacionadas à preservação ambiental, através dos modos de produção tradicionais. A aproximação dos conceitos de cadeias curtas e mercados aninhados também são trazidos ao debate, como formas alternativas de enfrentamento, ou adaptação, ao sistema agroalimentar hegemônico. Como principais resultados, os autores apontam para a criação de mecanismos de mercados durante a trajetória de desenvolvimento do capitalismo no território do Alto Camaquã, os quais acarretaram no processo de marginalização e exclusão dos pecuaristas familiares frente àqueles pecuaristas que se inserem na "lógica do mercado". A partir desta realidade, diversos agentes de desenvolvimento e atores sociais locais desenvolvem coletivamente o projeto Alto Camaquã. Configurado sob a lógica das estratégias endógenas de desenvolvimento rural, o projeto resulta em diversas ações de organização social em torno da pecuária familiar, como a criação de marca coletiva, visando a certificação e venda coletiva de produtos e serviços do território, incluindo o "Cordeiro do Alto Camaquã" (Matte et al., 2016).

Observa-se, a partir dos estudos descritos, pouca convergência dos resultados obtidos nas diferentes abordagens teórico-metodológicas utilizadas, sobretudo em relação à pecuária familiar. Os estudos voltados à competitividade das cadeias produtivas dedicam poucos esforços em explorar a heterogeneidade de formas existentes na pecuária ovina, fator que acaba por tomar a categoria dos pecuaristas familiares como ineficientes às cadeias produtivas. Por outro lado, aqueles estudos inclinados à investigação dos processos de desenvolvimento rural e do território, detêm-se, de modo geral, na produção de base familiar, considerando a diversidade presente em seus mercados e são motivados, em certa medida, pela tentativa de superar as limitações encontradas nas abordagens puramente econômica dos mercados.

Busca-se, através da elaboração de quadro comparativo (Quadro 1), não apenas salientar os distintos resultados obtidos sob diferentes lentes para o mesmo objeto de estudo, mas, sim, evidenciar resumidamente como formas distintas de interpretação da realidade podem vir a contribuir na transformação da mesma. Neste sentido, observam-se no campo empírico diferentes movimentos em torno da mesma realidade, a ovinocultura e seus mercados, com ações geradas por organizações sociais, agentes de desenvolvimento e o Estado, em grande medida balizadas no conhecimento científico gerado pelos estudos apontados.

Assim, nota-se grande proximidade de algumas políticas públicas com as indicações provenientes dos estudos econômicos dos mercados. Em seu Art. $4^{\circ}$, o texto de criação do Fundo de Desenvolvimento da Ovinocultura (Fundovinos) expressa os objetivos da política estadual, explicitando, apesar da amplitude do texto, menções especiais e diretas ao desenvolvimento setorial através do uso dos termos "produção", "competitividade", "cadeia produtiva" e "integração" (Rio Grande do 
Quadro 1. Principais resultados encontrados nos estudos sobre mercados da ovinocultura

\begin{tabular}{|l|l|}
\multicolumn{1}{|c|}{ Estudos econômicos dos mercados } & \multicolumn{1}{c|}{ Estudos sociológicos dos mercados } \\
\hline - Emergência do mercado da carne ovina; & - Desenvolvimento rural; \\
\hline - Cadeia complexa e desorganizada; & - Mercados aninhados; \\
\hline - Sazonalidade produtiva; & - Lógica local vs. mercados globais; \\
\hline - Falta de coordenação; & - Certificação participativa; \\
\hline - Alto índice de informalidade; & - Desenvolvimento territorial; \\
\hline - Estruturas de governança via mercado; & - Redes sociais; \\
\hline - Novos nichos de mercado; & - Construção social dos mercados; \\
\hline - Criação de valor através de estratégias de marketing; & - Qualidade associada; \\
\hline - Baixa competitividade; & - Identidade territorial; \\
\hline - Ambiguidades estre oferta e demanda; & - Cadeias curtas; \\
\hline - Alianças estratégicas para consolidação de mercado; & - Enraizamento; \\
\hline - Baixos níveis de modernização; & - Recursos comuns; \\
\hline - Heterogeneidade das cadeias de suprimentos; & - Construção social da qualidade; \\
\hline - Demanda atrelada a “aspectos culturais”. & - Vulnerabilidade. \\
\hline
\end{tabular}

Fonte: Elaborado pelos autores.

Sul, 1998). Ainda, o Programa de Desenvolvimento da Ovinocultura Gaúcha, através do Programa Mais Ovinos no Campo, concede incentivos financeiros para aumento do rebanho gaúcho, propondo-se a gerar condições de maior competitividade do setor ao potencializar a inserção no mercado de carne ovina e controle da "clandestinidade" (Secretaria da Agricultura Pecuária e Irrigação do Rio Grande do Sul, 2016).

Por outro lado, percebe-se uma inferência dos elementos tratados pelos estudos sociológicos dos mercados da ovinocultura na elaboração de políticas públicas orientadas para a construção de cadeias curtas, valorização da identidade e desenvolvimento territorial. Para Matte et al. (2016), a inserção dos pecuaristas familiares em mercados institucionais, como o Programa de Aquisição de Alimentos (PAA) e o Programa Nacional de Alimentação Escolar (PNAE), mostra-se uma estratégia de formação de cadeias curtas voltadas à relocalização alimentar.

Concepções originárias dos estudos sociológicos dos mercados também são identificadas na elaboração da recente política voltada à pecuária familiar no Rio Grande do Sul, o Programa Estadual de Desenvolvimento da Pecuária de Corte Familiar (PECFAM), em que parte dos objetivos dirige-se à adoção de tecnologias de produção preservacionistas, acesso a mercados diferenciados, estímulo ao cooperativismo e associativismo e estímulo à permanência no campo. Verifica-se também a influência de elementos dos estudos econômicos dos mercados nos objetivos dessa política, como a promoção da competitividade dos pecuaristas familiares, através da formalização do comércio, aumento nos índices produtivos e adoção de ferramentas de gestão (Rio Grande do Sul, 2010). A presença concomitante de elementos dos estudos econômicos e sociológicos dos mercados, visualizada nos objetivos da PECFAM, permite conceber a possibilidade de concordância entre as abordagens. Porém, um olhar crítico sobre estudos dos mercados na ovinocultura, assim como sua interação no campo das políticas públicas, possibilita exprimir algumas limitações dos estudos econômicos dos mercados, que comumente são postas como obstáculos à cadeia produtiva, ou mesmo são jogados na vala comum dos "aspectos culturais" naturais da ovinocultura.

Autores como Van Der Ploeg (2016) e Wilkinson (2008) atentam para o processo de dominação dos chamados "sistemas agroalimentares hegemônicos" no sentido de homogeneização da produção alimentar e dos mercados agroalimentares, geralmente fundamentados em conhecimento científico. De tal modo, reforça-se a necessidade de haver sempre um olhar crítico não somente sobre as ações no campo empírico, mas sobretudo naquelas que às fundamentam, em nosso caso, os estudos sobre os mercados da ovinocultura. Assim, a "desorganização da cadeia" é exposta na (quase) totalidade dos estudos 
conduzidos pela abordagem econômica dos mercados. Atribuída à falta de coordenação da cadeia, baixa integração técnico-econômica entre os segmentos, ou mesmo pela sazonalidade produtiva, o problema da desorganização é manifesto incondicionalmente quando a realidade não "acomoda-se" dentro dos pressupostos analíticos, refutando-se, assim, a possibilidade de formas alternativas de perceber a realidade. Perde-se, dessa forma, a possibilidade de descortinar novas possibilidades para os atores envolvidos na ovinocultura, como indica Van Der Ploeg (2016) no que se refere às "lacunas estruturais" existentes nos mercados gerais e que servem como abertura para formação de novos mercados.

A visão, de certa forma distorcida, da informalidade presente na ovinocultura, é muitas vezes relacionada a problemas de segurança alimentar e à perda da competitividade da cadeia. Porém, como mencionado por Wilkinson (2008), quaisquer formas de relações mercantis que não se encontrem coerentes com a lógica dos mercados globais são encaradas pelas abordagens analíticas do agronegócio como informais, e apontadas como entrave à "modernização do sistema agroalimentar". Conforme o autor, pode-se afirmar que a leitura da informalidade na ovinocultura, pelo prisma dos estudos econômicos dos mercados, tende a resultar no processo de legitimação dos seus próprios pressupostos, tornando-se, assim, uma temática central para análises com viés sociológico das relações de trocas. Além destes, um importante fator que acaba por ser menosprezado nas análises puramente econômicas dos mercados é o vínculo da ovinocultura gaúcha com o Bioma Pampa, "visto hoje como um dos biomas mais ameaçados pelo avanço da soja e das plantações de eucaliptos nas áreas de campo nativo" (Anjos et al., 2016, p. 305). Para Van Der Ploeg (2016), a preservação da biodiversidade, assim como a valorização da paisagem, o modo de produção tradicional, a cultura local, entre outros, podem ser vistos como um recurso comum a ser utilizado pelos atores sociais na construção de novos mercados.

Com base nas pesquisas apresentadas sobre os mercados da ovinocultura, sobretudo quanto às limitações encontradas nas abordagens econômicas dos mercados, e, considerando o debate sobre a concepção dos mercados pela nova sociologia econômica, ponderações são levantadas sobre formas alternativas para visualizar a ovinocultura da pecuária familiar e seus mercados. Neste sentido, o tópico seguinte aponta algumas reflexões e proposições acerca das possibilidades desta abordagem teórica na investigação dos mercados de categoria social até então subjugada pela academia, a pecuária familiar.

\section{Como pode a Nova Sociologia Econômica contribuir para o estudo dos mercados da ovinocultura na pecuária familiar?}

De modo geral, estudos voltados à ovinocultura no Rio Grande do Sul não atentam para a existência de diferentes categorias sociais na criação de ovinos, assim como são conduzidos mormente a partir de perspectivas economicistas. Quando colocados frente aos (poucos) estudos com viés sociológico dos mercados da ovinocultura tornam-se notórias as limitações analíticas das abordagens econômicas dos mercados, sobretudo ao não considerarem a heterogeneidade dos atores sociais e de suas relações, fatores presentes na pecuária ovina do estado.

Pondera-se que abordagens destinadas à análise da competitividade dos agentes e das cadeias produtivas pouco têm a contribuir com a investigação de uma categoria social que, segundo Waquil et al. (2016), caracteriza-se pelo maior grau de autonomia em relação aos mercados, e possui relações mercantis motivadas essencialmente pela reprodução social da família. Logo, confrontando as limitações identificadas nos estudos econômicos dos mercados da ovinocultura gaúcha com as especificidades da pecuária familiar, propõem-se algumas contribuições analíticas sob a perspectiva da nova sociologia econômica e, em seguida, algumas proposições gerais ao estudo dos mercados da ovinocultura de base familiar. Três elementos destacam-se como limitações daqueles estudos: (i) as assertivas sobre a desorganização da cadeia produtiva da ovinocultura, pautada essencialmente pela baixa integração entre os segmentos da produção rural, frigoríficos e varejista, pela sazonalidade produtiva, a falta de modernização dos segmentos produtivos (especialmente os produtores rurais) e a consequente dificuldade no atendimento da crescente "nova" demanda por carne ovina; (ii) o indicativo de um alto grau de informalidade, considerado o gargalo do setor e (iii) a desconsideração das características ambientais, sobretudo em relação ao Bioma Pampa. 
Em relação à falta de integração dos segmentos constituintes das cadeias da ovinocultura, são apontados por alguns autores, baseados principalmente na governança, estruturas de mercado e na gestão das cadeias de suprimentos, que a falta de mecanismos de coordenação (existência de uma empresa líder, organizações verticalizadas, certificações etc.) resultam no desalinhamento e dificuldades em alocar os recursos para o suprimento da crescente demanda (Canozzi, 2013; Malheiros, 2013). Assim, considerando o histórico individualismo e a desconfiança que caracterizam os pecuaristas familiares, somados à preferência na manutenção de certa autonomia em relação aos mercados (Neske, 2009; Ribeiro, 2009), entende-se cabível a falta de interesse pelos mesmos em vincularem-se (e dependerem) de agentes externos "à porteira".

Corroborando com as assertivas em relação às especificidades dos pecuaristas familiares elencadas acima, Anjos et al. (2016) destacam a falta de "engajamento cívico" dos ovinocultores envolvidos na iniciativa do Cordeiro Herval Premium, fator erigido como limitante ao desenvolvimento do projeto. A visão "desconfiada" em relação aos demais é resultado, segundo Osório (2016), do processo de formação histórica desta categoria social, marcada por constantes lutas pelo domínio da terra e pelo isolamento social. Tais fatores ampliam a parcialidade daqueles estudos, ao desconsiderarem a propensão ao comportamento individualista pelos pecuaristas familiares, suscitando, assim, investigações anteriores àquelas mais preditivas, em que o objetivo aproxima-se de uma das questões básicas da nova sociologia econômica, levantada por Wilkinson (2008), sobre em que encontra-se enraizada (a economia)?, a fim de esclarecer como se constitui a lógica dos pecuaristas em relação aos mercados.

Considerações acerca da sazonalidade produtiva são apontadas por Canozzi (2013) como um dos fatores limitadores ao desenvolvimento da ovinocultura gaúcha; porém, a partir de dados sobre o número de abates, importações de carne ovina e preços pagos aos produtores. Maciel et al. (2013) sugerem haver sazonalidade na produção de carne ovina no Rio Grande do Sul acompanhada de uma propensão ao consumo sazonal, o que não indica um problema para o setor, mas sim uma adaptação. Da mesma forma, os autores revelam a semelhança entre períodos de maior produção de carne ovina com a produção de campo nativo na região pampiana do Rio Grande do Sul (Maciel et al., 2013), revelando uma produção baseada em sistemas pecuários extensivos, corroborando, assim, com as afirmativas de Waquil et al. (2016) quanto aos sistemas de produção dos pecuaristas familiares e sua adaptação ao ambiente em que se inserem. Novamente, faz-se referência à Wilkinson (2008) ao indicar maior aprofundamento no entendimento das dimensões culturais e sociais em que estão imersos os atores sociais para compreender a construção dos mercados destes pecuaristas.

A falta de modernização, especialmente por parte dos pecuaristas, é destacada por Decker et al. (2016), ao sugerirem a necessidade de olhar para a produção ovina como um negócio empresarial, devendo haver uma reconfiguração dos sistemas de produção e de gestão das propriedades rurais, a fim de alcançarem maiores índices de produtividade e competitividade. Estudos realizados sobre os modos de vida e as estratégias de enfrentamento e adaptação dos pecuaristas familiares indicam existir uma forte vinculação com a natureza e formas tradicionais de produção, com uma lógica de produção e relações mercantis voltadas à viabilização das estratégias de reprodução social da família (Neske, 2009; Ribeiro, 2009; WAQUIL et al., 2016), deslegitimando, assim, a alegação de que estes devem adequar-se às inovações propostas para alavancar a competitividade das cadeias produtivas, e propiciando reflexões como: "a quem se destina a modernização da produção ovina?".

$\mathrm{O}$ último elemento destacado no conjunto de fatores determinantes da desestruturação da ovinocultura refere-se à existência de uma crescente e segmentada demanda e à baixa capacidade de atendê-la. Assim, estratégias de marketing são indicadas como formas de agregação de valor à cadeia produtiva (Malheiros, 2013; Viana et al., 2013). Questiona-se, assim, se tais estratégias de agregação de valor à cadeia produtiva resultam em benefícios para os atores locais, ou, como advertido por Van Der Ploeg (2016) e Wilkinson (2008), a uma lógica de homogeneização dos mercados agroalimentares como forma de dominação dos "sistemas agroalimentares hegemônicos". Neste sentido, experiências citadas por Matte et al. (2016) e Van Der Ploeg (2016) sobre a construção de mercados aninhados e de cadeias curtas para ovinocultura dos pecuaristas familiares apresentamse como alternativas para agregação de valor aos atores locais, e não somente ao produto. 
Também apontado como grande entrave da cadeia produtiva da carne ovina, o alto grau de informalidade é apontado por grande parte dos estudos econômicos dos mercados da ovinocultura. Apesar de não existir consenso quanto aos parâmetros utilizados para tal afirmativa, entre os principais fatores determinantes estão o consumo das famílias, a comercialização direta "face a face" por parte dos pecuaristas, e principalmente aspectos culturais atrelados aos pecuaristas. $\mathrm{O}$ consumo de animais (principalmente ovinos) nos estabelecimentos rurais é pratica comum aos pecuaristas familiares, visto que a produção para subsistência é elemento-chave desse modo de vida (Ribeiro, 2009). Somando-se a isso, as trocas de animais, assim como de mão de obra, para serviços esporádicos, é habitual entre os pecuaristas familiares (Waquil et al., 2016), assentando-se como práticas tradicionais desta categoria social.

A comercialização direta (entre produtores e consumidores, ou entre produtores), assim como o consumo destes animais em datas comemorativas, manifestam a existência de formas alternativas de mercados, construídos socialmente com base em relações de reciprocidade e enraizados em determinadas redes sociais. O olhar para estas práticas "informais" da ovinocultura do Rio Grande do Sul, a partir da noção de redes sociais, pode clarificar a complexidade presente nesta realidade, escapando do reducionismo proposto por análises puramente econômicas das relações sociais. Assim, o conhecimento da natureza das estruturas sociais, nas quais estão imersas as ações econômicas, e os mercados como construções sociais enraizados em uma rede social geram potenciais subsídios para perceber os processos de interação entre mercados e o desenvolvimento da ovinocultura.

Além destes elementos limitantes à compreensão da diversidade nos mercados da ovinocultura do Rio Grande do Sul, interações entre as cadeias produtivas e as características territoriais, sobretudo do Bioma Pampa, são também menosprezadas pelos estudos econômicos dos mercados. Nesse sentido, ressaltam-se as informações levantadas por Anjos et al. (2016) quanto à crescente ameaça sofrida pelos campos nativos do Bioma Pampa em relação ao avanço da área plantada de soja e florestas de eucalipto, sendo considerado hoje um dos biomas mais ameaçados de perda de biodiversidade. Atenta-se, dessa forma, para o processo de intensificação da agricultura e da pecuária, através da substituição das áreas de campo nativo, com consequências diretas aos fatores de vulnerabilidade dos pecuaristas familiares, os quais mantêm o modo de produção e de vida fortemente atrelado à natureza (Waquil et al., 2016).

O Quadro 2 exibe algumas contribuições da NSE como alternativas ao estudo dos mercados da ovinocultura na pecuária familiar, apontando as características desta categoria social em relação aos aspectos limitantes dos estudos econômicos e proposições de análise.

A partir destas proposições, sugere-se uma investigação visando identificar como se dá a construção social destes

Quadro 2. Contribuições da Nova Sociologia Econômica para o estudo dos mercados da ovinocultura na pecuária familiar

\begin{tabular}{|l|l|}
\hline \multicolumn{1}{|c|}{$\begin{array}{c}\text { Limitações dos estudos econômicos dos } \\
\text { mercados }\end{array}$} & \multicolumn{1}{c|}{ Proposições da nova sociologia econômica } \\
\hline \multirow{2}{*}{ Falta de integração } & Individualismo e “desconfiança" dos pecuaristas familiares. \\
\cline { 2 - 3 } & Investigações básicas - "em que se encontra enraizada a economia?" \\
\hline \multirow{2}{*}{ Sazonalidade produtiva } & Propensão de adaptação ao ambiente - modos de vida. \\
\cline { 2 - 3 } Falta de modernização & Compreensão dos aspectos culturais e sociais dos pecuaristas. \\
\hline \multirow{2}{*}{ Relação oferta $\times$ demanda } & Reprodução social das famílias como lógica de produção e comercialização. \\
\cline { 2 - 2 } & A quem se destina a modernização da produção ovina? \\
\hline \multirow{2}{*}{ Alto grau de informalidade } & Relações mercantis marcadas pela autonomia dos mercados. \\
\cline { 2 - 2 } & Construção de mercados aninhados e cadeias curtas. \\
\hline \multirow{2}{*}{ Aspectos do território } & Produção para subsistência e trocas de animais. \\
\cline { 2 - 2 } & Estudo das redes sociais e relações de reciprocidade. \\
\hline
\end{tabular}

Fonte: Elaborado pelos autores. 
mercados, a partir do conhecimento de sua natureza e funcionamento. Assim, inicialmente torna-se necessária uma minuciosa análise sobre a formação histórica da ovinocultura, sua interação com os processos de desenvolvimento do território, destacando os papel da pecuária familiar e os aspectos culturais, políticos, sociais de maior influência, buscando identificar os principais elementos em que estão imersas as redes sociais daquela categoria social. Possibilita-se, assim, a posterior inferência de distintas formas de construção social dos mercados com os processos de desenvolvimento tomados em diferentes tempos e locais.

A verificação das redes sociais formadas pelos pecuaristas familiares no contexto territorial que estão inseridos, suas formas de relação (frequência, similaridade e especificidade dos laços) e a posição dos atores nas redes também são elementos analíticos de suma importância para compreensão do funcionamento dos mercados em que estão inseridos, assim como a heterogeneidade dos mesmos. A consequente caracterização das formas de mercados atualmente presentes na ovinocultura dos pecuaristas familiares, sejam mercados tradicionais ou emergentes, apresenta-se como importante ferramenta para auxiliar nas estratégias de valorização do território, preservação do ambiente e enfrentamento dos fatores de vulnerabilidade dos pecuaristas familiares, através do conhecimento prévio de sua realidade diante da prescrição de ações, públicas ou privadas, de intervenção nessa realidade.

Indica-se, assim, a condução de pesquisas que visem compreender os processos de formação, configuração e funcionamento dos mercados da ovinocultura na pecuária familiar, indo além da análise utilitarista de produção e consumo, ou seja, que intentem verificar as especificidades presentes na realidade, partindo do entendimento de que as ações econômicas são modos de ações sociais, e que as instituições que regem os mercados foram construídas socialmente.

\section{Considerações finais}

Este ensaio buscou traçar um panorama dos estudos que vêm sendo conduzidos sobre os mercados da ovinocultura e, a partir da reflexão sobre as contribuições da nova sociologia econômica, indicar alternativas para o estudo dos mercados da pecuária familiar do Rio Grande do Sul. Os estudos concentrados na análise setorial e com forte ênfase nos aspectos econômicos comumente são empregados nas questões relativas aos mercados da ovinocultura, em grande medida desconsiderando a presença dos pecuaristas familiares, vistos de forma marginal e como resíduos a serem superados pela modernização das cadeias produtivas. Por outro lado, aqueles estudos dedicados às produções rurais de base familiar, ao mesmo tempo em que consideram a heterogeneidade existente nos seus mercados, são restritos no âmbito da pecuária, essencialmente em relação aos mercados da ovinocultura.

Percebeu-se na nova sociologia econômica uma corrente teórica que, a partir das limitações existentes nos estudos dos mercados baseados na tradição econômica clássica, propõe-se a desvendar as particularidades e sinuosidades presentes naquelas estruturas sociais que mais impactam na transformação das sociedades, os mercados. Dessa forma, a partir da concepção de que os mercados são construções sociais, enraizadas em estruturas e redes sociais, acredita-se que esta perspectiva mostra-se relevante no estudo da natureza e do funcionamento dos mercados da ovinocultura na pecuária familiar, possibilitando, ainda, a categorização dos tipos de mercados. Os diferentes tipos e graus de enraizamento que os mercados podem apresentar são questões que vêm sendo aprofundadas largamente pela perspectiva da nova sociologia econômica. Os três modos de organização social do processo econômico que coexistiram ao longo da história (Polanyi, 1980) são uma forma clássica de exemplificação desta análise, em que a reciprocidade, a redistribuição e o intercâmbio e mercado são maneiras de interpretar a constituição dos mercados analisados. A partir do entendimento dos mercados como um local de trocas, como um ordenador social e como uma construção social, Schneider (2016) sugere uma tipologia mais atualizada e voltada aos mercados da agricultura familiar; porém, percebe-se também a presença de diferentes formas e níveis de enraizamento.

A ideia de elaboração de tipologias dos mercados, partindo da contribuição seminal de Polanyi (1980), como da recente proposição de Schneider (2016), mostra-se pertinente ao estudo dos mercados da ovinocultura na pecuária familiar, devido à possibilidade de conceber o processo de construção das instituições que regem os mercados e, ainda, identificar a heterogeneidade. Dessa 
forma, alguns elementos-chave devem ser ponderados, como as relações de trocas do tipo "face a face" entre os produtores, muito realçadas na literatura sobre a pecuária familiar e marcadamente próximas aos tipos de relações exploradas pela teoria da reciprocidade, em que a confiança é o principal condutor e mecanismo de manutenção das relações e das redes sociais (Radomsky \& Schneider, 2007).

Os mercados emergentes para a ovinocultura na pecuária familiar, como o caso dos mercados institucionais e da marca coletiva desenvolvidos no território do Alto Camaquã (RS) (Matte et al., 2016), nos quais o estado constitui um importante dispositivo, e o Genuíno Cordeiro Texel (Van Der Ploeg, 2016), mercado construído a partir da organização social dos atores locais, apresentam-se também como elementos-chave que incrementam a elaboração de tipologias para os mercados da pecuária familiar. Neste sentido, a proposição teórica de mercados aninhados, como formas de construção social de mercados alternativos aos mercados gerais, é oferecida por Van Der Ploeg (2016) como uma potencial forma de estudo dos mercados emergentes da ovinocultura.

Considerando as especificidades dos mercados da pecuária familiar, sobretudo da ovinocultura e, ainda, as correntes teóricas indicadas para dar suporte na análise destas, entende-se pertinente a elaboração de uma tipologia para os mercados da ovinocultura na pecuária familiar do Rio Grande do Sul à luz da nova sociologia econômica. A melhor compreensão da natureza e funcionamento dos mercados da ovinocultura, a partir de uma tipologia que evidencie suas peculiaridades, resulta em potencial ferramenta para elaboração de políticas públicas direcionadas à categoria social da pecuária familiar, assim como para formulação de estratégias e tomada de decisões pelos ovinocultores.

\section{Referências}

Anjos, F. S., Silva, F. N., \& Pollnow, G. E. (2016). O sinuoso caminho de construção da qualidade na ovinocultura pampiana: O caso do cordeiro Herval Premium. Estudos Sociedade e Agricultura, 24(1), 287-310.

Barchet, I. (2012). Avaliação da competitividade da cadeia produtiva de carne ovina no Rio Grande do Sul (Dissertação de mestrado). Universidade Federal de Santa Maria, Santa Maria.
Canozzi, M. E. A. (2013). Caracterização da cadeia produtiva da carne ovina no Rio Grande do Sul, Brasil. Pesquisa Agropecuária Gaúcha, 19(1-2), 130-139.

Decker, S. R. F., Fernandes, D. A. C., \& Gomes, M. C. (2016). Gestão competitiva na produção de ovinos. Revista Agropampa, 1(1), 113-122.

Expointer. (2016). A ovinocultura moderna - por onde começar a mudança? Recuperado em 04 de outubro de 2016, de http://www.expointer.rs.gov.br/circuito-depalestras-a-ovinocultura-moderna-por-onde-comecara-mudanca-57bf6e6c398f0

Felice, Â., Maciel, R. G., \& Viana, J. G. A. (2011, outubro 24-26). Produção de carne ovina no Rio Grande do Sul: análise de tendência e sazonalidade produtiva. In III Salão Internacional de Ensino, Pesquisa e Extensão da Unipampa (cd-rom). Uruguaiana: SIEPE.

Fernandes, V. D., \& Miguel, L. A. (2016). A presença histórica da pecuária familiar na região da Campanha do Rio Grande do Sul (Santana do Livramento, século XIX). In P. D. Waquil, M. Z. Neske, A. Matte, M. F. S. Borba (Eds.), Pecuária familiar no Rio Grande do Sul: história, diversidade social e dinâmicas de desenvolvimento. Porto Alegre: Editora da UFRGS.

Gonçalves, O. J., \& Martes, A. C. B. (2015). Democracy, markets, and rural development: the case of Small goat-milk farmers in the brazilian northeast. Economia e Sociologia, 16, 25-33.

Granovetter, M. (1985). Economic action and social structure: the problem of embeddedness. American Journal of Sociology, 91(3), 481-510.

Instituto Brasileiro de Geografia e Estatística - IBGE. (2007). Utilização das terras dos estabelecimentos agropecuários. In IBGE, org. Censo agropecuário de 2006 : resultados preliminares. Rio de Janeiro: IBGE.

Instituto Brasileiro de Geografia e Estatística - IBGE. (2016). Efetivo de rebanhos, Ovinos. Recuperado em 01 de julho de 2016, de http:/ / www.sidra.ibge.gov.br/bda/ pecua/default.asp? $\mathrm{t}=2$

Maciel, R. G., Silveira, V. C. P., \& Viana, J. G. A. (2013, julho 21-24). Aspectos relacionados a sazonalidade do mercado de carne ovina no Rio Grande do Sul. In Anais do $51^{\circ}$ Congresso da Sociedade Brasileira de Economia, Administração e Sociologia Rural (pp. 1-13). Belém: SOBER.

Malheiros, M. A. C. (2013). O uso das estratégias de marketing para criação de valor na cadeia produtiva da ovinocultura: 0 elo do produtor (Dissertação de mestrado). Universidade de Santa Cruz do Sul, Santa Cruz do Sul.

Matte, A., Neske, M. Z., Borba, M. F. S., Waquil, P. D., \& Schneider, S. (2016). Mercado de cadeias curtas na pecuária familiar: Um processo de relocalização no território do Alto Camaquã no Rio Grande do Sul/ Brasil. Redes, 21(3), 137-158.

Neske, M. Z. (2009). Estilos de agricultura e dinâmicas locais de desenvolvimento rural: $O$ caso da pecuária familiar no 
Território Alto Camaquã do Rio Grande do Sul (Dissertação de mestrado). Universidade Federal do Rio Grande do Sul, Porto Alegre.

Niederle, P. A., Schubert, M. N., \& Schneider, S. (2014). Agricultura familiar, desenvolvimento rural e um modelo de mercados múltiplos. In S. M. Doula, A. L. C. Fiúza, E. C. Teixeira, J. D. Reis \& A. L. R. Lima (Orgs.), A agricultura familiar em face das transformações na dinâmica recente dos mercados. Viçosa: Suprema.

Osório, H. (2016). Pastores e lavradores do Rio Grande, séculos XVIII e XIX. In P. D. Waquil, M. Z. Neske, A. Matte, M. F. S. Borba (Eds.), Pecuária familiar no Rio Grande do Sul: história, diversidade social e dinâmicas de desenvolvimento. Porto Alegre: Editora da UFRGS.

Polanyi, K. (1980). A grande transformação: as origens da nossa época. Rio de Janeiro: Editora Campus.

Radomsky, G., \& Schneider, S. (2007). Nas teias da economia: o papel das redes sociais e da reciprocidade nos processos locais de desenvolvimento. Sociedade $e$ Estado, 22(2), 249-284.

Raud-Mattedi, C. (2005). Análise crítica da Sociologia Econômica de Mark Granovetter: os limites de uma leitura do mercado em termos de redes e imbricação. Política e Sociedade, 4(6), 59-82.

Ribeiro, C. M. (2009). Estudo do modo de vida dos pecuaristas familiares da Região da Campanha do Rio Grande do Sul (Tese de doutorado). Universidade Federal do Rio Grande do Sul, Porto Alegre.

Rio Grande do Sul - RS. (1998, junho 08). Lei no 11.169, de 08 de junho de 1998. Dispõe sobre a produção, circulação e comercialização da carne ovina, lã e seus derivados, cria o Fundo de Desenvolvimento da Ovinocultura do Estado-FUNDOVINOS. Assembleia Legislativa do Estado do Rio Grande do Sul, Rio Grande do Sul.

Rio Grande do Sul - RS. (2010, setembro 13). Lei no 13.515, de 13 de setembro de 2010. Institui o Programa Estadual de Desenvolvimento da Pecuária de Corte Familiare dá outras providências. Assembleia Legislativa do Estado do Rio Grande do Sul, Rio Grande do Sul.

Schneider, S. (2016). Mercados e agricultura familiar. In F. C. Marques, M. A. Conterato, \& S. Schneider. Construção de mercados e agricultura familiar: desafios para o desenvolvimento rural. Porto Alegre: Editora da UFRGS.

Secretaria da Agricultura Pecuária e Irrigação do Rio Grande do Sul-SEAPI. (2012). Levantamento pecuário 2012. Recuperado em 01 de julho de 2016, de http:/ / www. dda.agricultura.rs.gov.br/conteudo/3181/?Secretaria_ da_Agricultura_divulga_dados_do_Levantamento_Pecu\%C3\%A1rio_2012_do_RS

Secretaria da Agricultura Pecuária e Irrigação do Rio Grande do Sul-SEAPI. (2016). Mais ovinos no campo. Recuperado em 01 de outubro de 2016, de <http: / / www.agricultura. rs.gov.br/conteudo/1033/?Mais_Ovinos_no_Campo
Serviço Brasileiro de A poio às Micro e Pequenas Empresas - SEBRAE. (2016). IV seminário de ovinos da campanha será realizado em Santana do Livramento. Recuperado em 04 de outubro de 2016, de http: / / www.sebrae-rs.com. br/index.php/noticia/3978-iv-seminario-de-ovinos-dacampanha-sera-realizado-em-santana-do-livramento

Silveira, H. S. (2005). Os mercados da ovinocultura na pecuária familiar: Proposições analíticas da nova sociologia econômica (Dissertação de mestrado). Universidade Federal do Rio Grande do Sul, Porto Alegre.

Simpósio de Ovinos - SIMPOVINOS. (2016). II Simpósio de ovinos. Recuperado em 04 de outubro de 2016, de http: / / simposiodeovinos.blogspot.com.br/p/programacao.html Steiner, P. (2006). A sociologia econômica. São Paulo: Atlas.

Swedberg, R. (2004). Sociologia econômica: Hoje e amanhã. Tempo Social, 16(2), 7-34.

Van Der Ploeg, J. D. (2016). Mercados aninhados recém criados: uma introdução teórica. In F. C. Marques, M. A. Conterato, \& S. Schneider, (Eds.), Construção de mercados e agricultura familiar: desafios para o desenvolvimento rural. Porto Alegre: Editora da UFRGS.

Viana, J. G. A. (2012). Evolução da produção ovina no Rio Grande do Sul e Uruguai: Análise comparada do impacto da crise da lã na configuração do setor (Tese de doutorado). Universidade Federal do Rio Grande do Sul, Porto Alegre.

Viana, J. G. A., \& Silveira, V. C. P. (2009). Cadeia Produtiva da ovinocultura no Rio Grande do Sul: Um estudo descritivo. Revista em Agronegócios e Meio Ambiente, 2(1), 9-20.

Viana, J. G. A., Revillion, J. P. P., \& Silveira, V. C. P. (2013). Alternativa de estruturação da cadeia de valor da ovinocultura no Rio Grande do Sul. Revista Brasileira de Gestão e Desenvolvimento Regional, 9(1), 187-210.

Viana, J. G. A., Silveira, V. C., Arbage, A. P., Machado, J. A. D. (2012). Governance and transaction costs in the sheep production chain in Rio Grande do Sul, Brazil. African Journal of Business Management, 6(11), 4376-4385.

Waquil, P. D., Neske, M. Z., Matte, A., \& Borba, M. F. S. (2016). Pecuária familiar no Rio Grande do Sul: História, diversidade social e dinâmicas de desenvolvimento. Porto Alegre: Editora da UFRGS.

Wilkinson, J. (2008). Mercados, redes e valores: o novo mundo da agricultura familiar. Porto Alegre: Editora UFRGS.

Wilkinson, J. (2016). Os mercados não vem mais do "Mercado". In F. C. Marques, M. A. Conterato, \& S. Schneider (Eds.), Construção de mercados e agricultura familiar: Desafios para o desenvolvimento rural. Porto Alegre: Editora da UFRGS.

Zero Hora - ZH. (2012). Abate clandestino de ovinos chega a 92\% no Brasil. Recuperado em 03 de outubro de 2016, de https:/ / gauchazh.clicrbs.com.br/economia/ noticia / 2012/07/abate-clandestino-de-ovinos-chegaa-92-no-brasil-3825590.html 